\title{
Designing a Microstructural Array Associated with Hardness of Dual-phase Cu-Zn Alloy Using Investment Casting
}

\author{
Gabriel Iecks ${ }^{a}$, Luiz Michel Aram Maiolo ${ }^{b}$, Ausdinir Danilo Bortolozo ${ }^{b}$, Wislei Riuper Osório ${ }^{a, b} *$ ([) \\ ${ }^{a}$ Faculdade de Ciências Aplicadas - FCA, Centro de Pesquisa de Materiais Avançados - CPMMA, \\ Universidade Estadual de Campinas - UNICAMP, 1300, Limeira, SP, Brasil \\ ${ }^{b}$ Faculdade de Tecnologia, Universidade Estadual de Campinas - UNICAMP, Limeira, SP, Brasil
}

Received: December 04, 2017; Revised: February 14, 2018; Accepted: March 19, 2018

\begin{abstract}
A comparative investigation on the microstructural morphologies and hardness values of $\mathrm{Cu}-35$ wt.\% $\mathrm{Zn}$ and $\mathrm{Cu}-30 \mathrm{wt} . \% \mathrm{Zn}$ with $1.5 \mathrm{wt} . \% \mathrm{Al}$ content is provided. Distinctive specimens by using traditional investment casting were produced. Specimens withdrawn from distinct locations along the castings were thermally and microstructural analyzed. Thermally and chemically induced microstructural modifications affecting the microstructure and hardness are discussed. It is found that components (specimens) located at different positions along of the pattern tree casting have distinctive hardness values. This is associated with $\mathrm{Cu}$ segregation and cooling rate. It is also found that solidified piece under a cooling rate $\sim 0.12 \mathrm{~K} / \mathrm{s}$ has hardness $20 \%$ higher than the specimen solidified under $0.07 \mathrm{~K} / \mathrm{s}$. Duplex brass with Widmanstätten structure constitutes the resulting microstructure array. This seems to be associated with $\mathrm{Al}$ content, while both $\mathrm{Zn}$ and $\mathrm{Al}$ contents are associated with cooling rate as responsible parameter to induce Widmanstätten structure formation.
\end{abstract}

Keywords: $\mathrm{Cu}$-Zn alloys, investment casting, microstructure, solidification, hardness.

\section{Introduction}

In order to design the performance of manufactured component as a function of the processing variables, a combination of determined hall of properties is very important. An alternative way to affect the resulting performance of a component is controlling of the resulting microstructural morphology by manipulating the processing variables. Some investigations have been developed, demonstrating the correlation between resulting microstructure array and properties ${ }^{1-10}$. Based on this, in this present study, corroborations with some guidelines in order to preprogram a desired property intimately associated with microstructural array concerning to brass alloys applied in jewelry sector are carried out.

In the 1980's a number of investigations concerning to brass, jewelry, gold jewelry and investment casting have contributed with both technical and scientific aspect. Ott and collaborators ${ }^{11-13}$ and Nielsen ${ }^{14}$ have demonstrated factors affecting the quality surface of castings and nucleation characterization inferring into the liquid and final surface of the castings. Zinc content effect ${ }^{12}$ and gas pressure in mold during casting, which also affect the quality of the casting produced have also been reported by Ott et al. ${ }^{12,13}$. A number of other important contributions concerning to $\mathrm{Cu}$ alloys (in particular brasses) involving thermodynamic aspects and some properties has been reported ${ }^{5-8,13-18,22,23}$. Recently, it has been published a paper ${ }^{18}$ discussing a new shell casting for investment casting for distinctive materials and applications. However, it is perceived that since the 80 's decade there exists a lack of a contribution mixture between technical and scientific aspects directly focused on the jewelry industry. This contribution should indicate a range of operational parameters such as melting temperature correlated with piece volume and dimension, the corresponding position of the piece inside the casting, which affects significantly the resulting macrosegregation, cooling rate, visual/surface quality, mechanical properties and gold-plating quality. In this sense, this proposed investigation reasonably corroborates in this direction based on their obtained experimental results. Since their operational parameters are discussed and possibly controlled, a certain cost and desired performance (e.g. hardness and surface polishing) correlated with cooling rate can be attained.

The combination of workability, thermal and electrical conductivity, good wear and mechanical behavior, associated with reasonable corrosion resistance and low relative $\operatorname{cost}^{5,6}$, a number of brasses in distinctive industrial applications (e.g. automobile, electronic, energy, etc.) are widely manufactured ${ }^{1-3,5,6}$. It is worthy noted that during the last 30 years the tribological behavior of these brasses has also been reported $d^{5,7,8}$. From the brass alloys required to bearing application, both $\mathrm{Cu}$ content ( $>$ than 60 wt. \%) and partial $\mathrm{Pb}$ content (of about $3 \%$ ) are considered. This induces to a reasonable formability in a cold working and facilitated machining ${ }^{6}$. 
$\mathrm{Cu}-\mathrm{Zn}$ is an important and well-known binary alloy system and at $\mathrm{Cu}$-rich side has widely been investigated ${ }^{9}$. Considering the group of non-ferrous metals, $\mathrm{Cu}-\mathrm{Zn}$ alloys constitute a group of alloys in industrial application widely used $^{10}$. Brasses are commonly produced in various domains into the foundry industry in order to manufacture some distinctive components used e.g. in: civil engineering, aircraft industry, and machine buildings. The jewelry industry also constitutes an industrial sector, which has widely used these brasses to produce distinct components. Although the manufacturing of the brasses in jewelry parts has been carried for a long time, it is considered reasonably new the trade-off between performance and cost associated with environmentally-friendly aspect.

From the metallurgical point of view, both the alpha and alpha + beta (called as dual-phase) brasses are commonly used. It is known that the investment casting was established over 5500 years ago ${ }^{19}$. This process is the proven technology to economically produce metal forms with complex geometries, narrow tolerances, great mechanical properties and superior surface finish. As aforementioned, there are various components manufactured using this process (e.g. turbine blades, dental crowns and fixtures, gears, jewelry, etc. $)^{19,20}$. Prototypes are rapidly produced from a customer furnished computer-aided design solid model. These associated with investment casting can be a powerful tool to casting industry with near-net shape, environmental-friendly, relative low cost and preprograming resulting properties.

Since the brasses offer a friendly-environmental aspect, in order to improve the resulting performance based on the applied process variables the jewelry sector has been taken attention. In this sense, a group of small business companies from the gold-plating sector and their association (i.e. Association of Gold-plated Jewelry from Limeira city, the Associação Limeirense de Joias - $A L J^{21}$ ) have induced reinforcements to improve the sector. Although the goldplating jewelry industry is worldwide recognized, Limeira city (São Paulo state, Brazil) is renowned as the gold-plating capital city in $\mathrm{Brazil}^{21}$. Approximately 500 companies of semi jewelry production are located at Limeira city. It has been stated $^{21}$ that their monthly production attains of about 50 ton. Based on the friendly-environmental aspect and compatible relative cost associated with reasonable performance (i.e. unsoundness, strength, hardness, ductility, workability and corrosion/oxidation behavior), the thermal and compositional aspects and operational parameters can be used to control of the resulting microstructural array of these semi jewelry pieces. As a direct consequence, the desired performance can also appropriately be attained.

From the metallurgical point of view, an investigation concerning to thermally and chemically induced microstructural modifications, which affect the hardness of a brass $(\mathrm{Cu}-\mathrm{Zn}$ based) alloy seems to corroborate with up-dating knowledge.
This is scarce in literature, in particular considering duplex brasses applied to jewelry and semi-jewelry industries. Although this study is majority focused on jewelry industry, it is well known that bearing, medical and a number of other industries can be benefited. The novelty concerns to the fact of the chemical and thermal aspects are intimately associated with the resulting hardness and workability of the proposed components and investment casting parameters (i.e. location at pattern tree, molten temperature and cooling rate). A comparison between two distinctive $\mathrm{Zn}$ contents (i.e. 30 and 35 wt. \%) and two different component shapes of a $\mathrm{Cu}-\mathrm{Zn}-1.5 \mathrm{Al}$ alloy is carried out.

\section{Experimental Procedure}

\subsection{Materials and samples preparations}

Commercial pure $\mathrm{Cu}$ (99.991 wt. \%), Zn (99.993 wt. \%), and $\mathrm{Al}(99.97$ wt. \%) are used. Two distinctive brasses with 1.5 wt. $\%$ Al content are produced: $i$ ) Cu-30 wt. \% Zn (C30ZA) and ii) $\mathrm{Cu}-35$ wt. \% $\mathrm{Zn}$ (C35ZA). An inductive furnace is utilized to prepare the examined alloys samples. X-ray fluorescence (XRF) and EDS (energy dispersive spectroscopy) techniques are used to confirm the alloys compositions. Table 1 shows the chemical compositions of each examined brasses samples constituting the semi jewelry (ring) pieces. In the shell-building, gypsum to constitute the ceramic shell is used. The brass components with shaped-ring are called as "Model" 1, 1B, 2 and 3. Model 1 and 2 have designated composition as C35ZA since their chemical compositions and shapes are similar (i.e. $\sim 35 \mathrm{wt} . \% \mathrm{Zn}$ and $1.5 \mathrm{wt} . \% \mathrm{Al}$ ). They were obtained (withdrawn) from distinct locations at the pattern tree (casting). The component Model 1B has a same shaped-ring of Models 1 and 2 containing $30 \mathrm{wt} \%$ Zn content (designated as C30ZA). Model 3 has a different shaped-ring, but it has a similar chemical composition when compared with Models 1 and 2. Models 1 and 2 are located approximately of 40 and $95( \pm 3) \mathrm{mm}$ from the intersection between "main sprue" and "runner" of the proposed tree casting considering their corresponding "feed sprue", as schematically shown in Fig. 1(a).

Fig. 1(b) and 1(c) shows the corresponding shape-ring of the proposed brass samples, i.e. called as Model 1 and Model 3. At the top of the steel flask (tubes) containing the pattern tree are located the thermocouples, as also shown in Fig. 1. Thermocouples (Type K) strategically located at "main sprue" are used to recorded the cooling curves of each examined Model 1 at points \#1 and \#2, as show in Fig. 1(a). The cooling rates were determined based on the transformations detected in the experimental temperature vs. time curves considering those specific thermocouple locations (points \#1 and \#2), as shown in Fig. 1(a).

A certain volume of molten using a stainless steel ladle is poured out into the cavity of the tree (mold). After 
Table 1. Chemical compositions of produced Models and its corresponding pure materials.

\begin{tabular}{lccccccc}
\hline & \multicolumn{7}{c}{ Chemical Composition (wt. \%) } \\
\hline Model 1 & Cu & Zn & Al & Si & Sn & Pb & Fe \\
Model 1B & balance & 34.5 & 1.48 & $<0.02$ & $<0.02$ & $<0.01$ & 0.032 \\
Model 2 & balance & 30.2 & 1.66 & $<0.03$ & $<0.03$ & $<0.01$ & 0.028 \\
Model 3 & balance & 33.7 & 1.51 & $<0.02$ & $<0.03$ & $<0.02$ & 0.030 \\
Al ingot & balance & 34.2 & 1.49 & $<0.03$ & $<0.03$ & $<0.01$ & 0.033 \\
Cu ingot & $<0.001$ & N/A & balance & 0.02 & N/A & $<0.02$ & 0.03 \\
Zn ingot & balance & $<0.001$ & $<0.001$ & N/A & N/A & $<0.001$ & $<0.001$ \\
\hline
\end{tabular}

$\mathrm{N} / \mathrm{A}=$ not available.

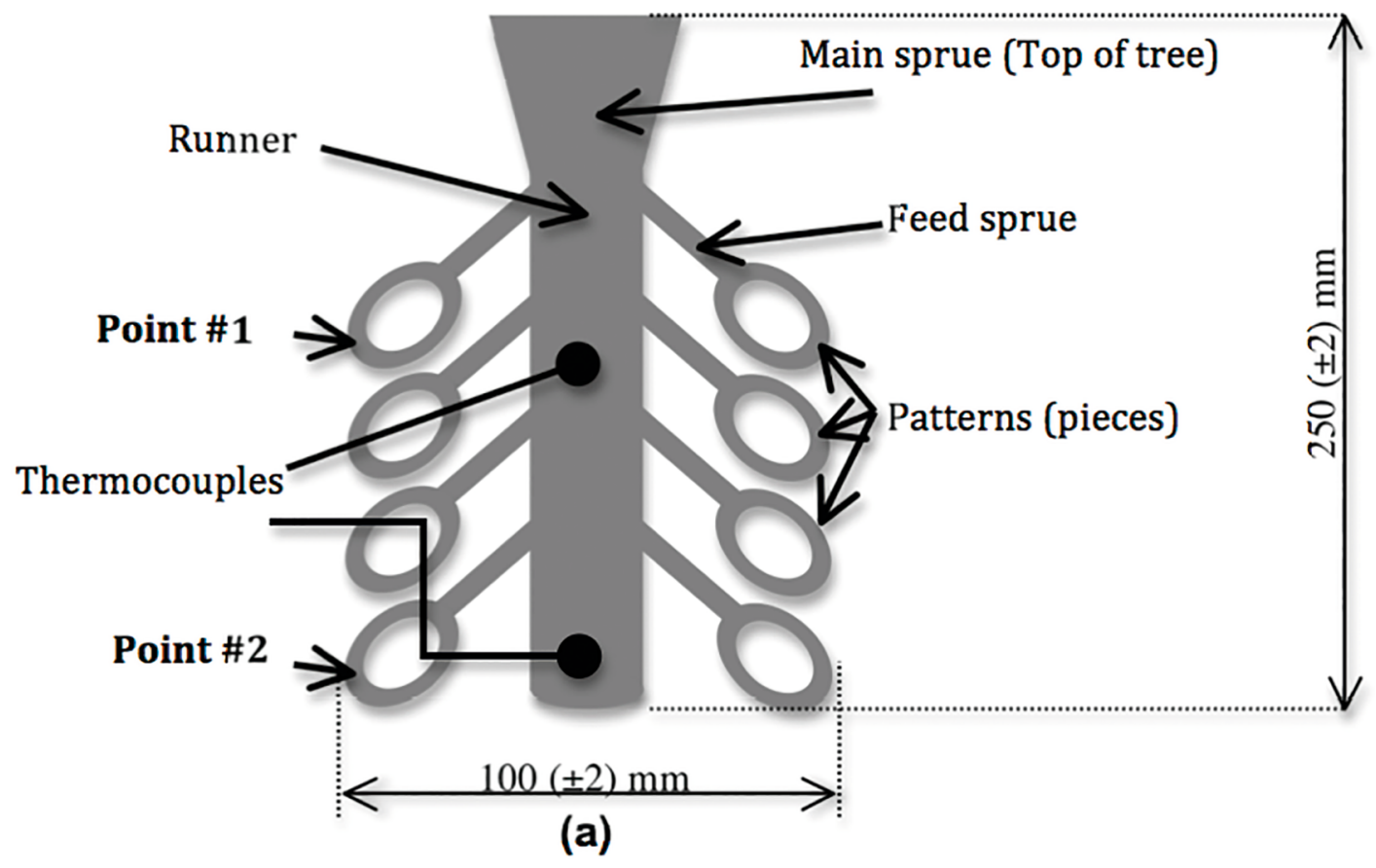

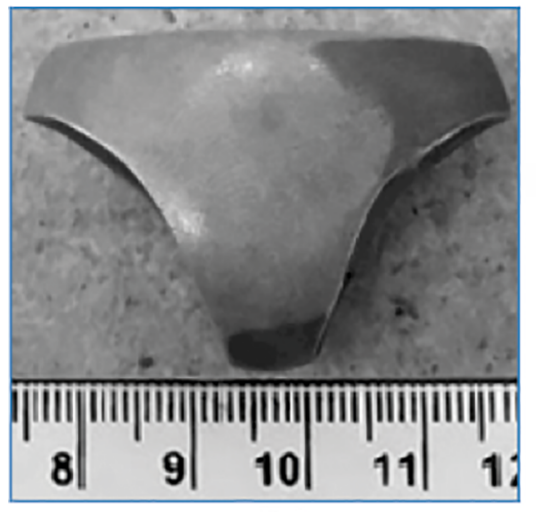

(b)

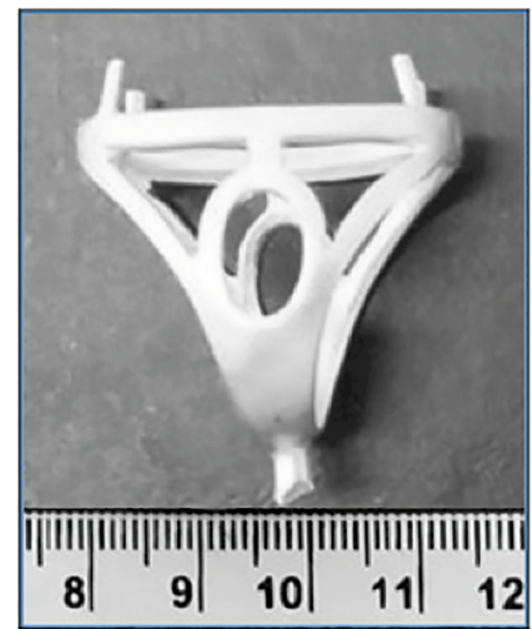

(c)

Figure 1. (a) Schematic representation of a typical tree casting containing $\sim 40$ pieces: Moldes 1 and 2 (b). Although differently located at pattern tree casting, the Models 1 and 2 have similar chemical compositions (i.e. $\sim 35 \mathrm{wt} \% \mathrm{Zn}$ and $1.5 \mathrm{wt} . \% \mathrm{Al}$ ), and due to this reason are designated as C35ZA. Model 3 (c) has a distinct shaped-ring, but it has a similar composition to Models 1 and 2. 
solidification, the casting trees were knocked out for remove the involving capsules of gypsum and brass samples (patterns) were cut-off and metallographically prepared.

\subsection{Microstructural observation and hardness}

The brass samples were mounted into molding epoxy and sequentially were ground using grit silicon carbide papers (up to $1200 \mathrm{mesh}$ ), washed into deionized water, degreased with acetone and dried by forced natural airflow. A $0.3 \mu \mathrm{m}$ alumina paste/suspension for polishing was used. In order to reveal the resulting microstructure array for all examined brasses, a solution constituted of $10 \%$ (vol.) ammonium persulfate during 2 and $4 \mathrm{~s}$ was used. Although there are other etchants to reveal the brass microstructure (i.e. $\mathrm{FeCl}_{3}$ into $\mathrm{HCl}$ solution ${ }^{5,10,22}$, and a $\mathrm{HNO}_{3}$ solution ${ }^{23}$ ), the ammonium persulfate has produced satisfactory micrographs.

The grain sizes (GS) and the average lengths of needle-like or plate-like Widmanstätten were determined when were depicted. From each selected position lengthwise of each casting piece of about 10 20 values were measured. The averages and its corresponding error ranges were also determined.

Brinell hardness tests were carried out using a $5 \mathrm{~mm}$ diameter steel ball and a $62.5 \mathrm{kgf}$ load (HBS 5/62.5, ASTM E10). The averages of HBS values were determined considering of about 15 measurements for each examined sample. Vickers microhardness were also performed indenting predominantly $\alpha$ phase and $\beta$ phase using loading of 25 and $50 \mathrm{gf}$ (ASTM E384). For microhardness measurements, at least 5 points for each one of the examined samples were tested, and arithmetical mean values were determined.

\section{Results and Discussion}

\subsection{Resulting microstructure array: distinctive positions at casting}

A comparison between the resulting microstructural array of similar shape and chemical composition of the pieces (Model 1, as shown in Fig. 1b) varying their corresponding positions along the casting (pattern tree) was provided. Typical micrographs of the as-cast brass C35ZA samples are depicted in Fig. 2.

Fig. 2 (a) and (c) corresponds to that of the resulting microstructure at point \# 1, which is located at the top of the casting. On the other hand, the obtained microstructural array of the C35ZA alloy is correlated with the bottom of the casting (pattern tree), as shown in Fig. 2(b) and (d). Based on these microstructural observations, it can be seen that the classic Widmanstätten structures ${ }^{22-24}$ are formed.

The $\alpha$ phase (needle-like) Widmanstätten are predominantly formed, as depicted in Fig. 2 (a) and (c). The plate-like Widmanstätten structures are predominantly shown in Fig. 2(b) and (d). The resulting microstructures clearly reveal that duplex phase ( $\alpha$ plus $\beta$ ) are constituted. The phase $\alpha$ and $\beta$ phases are represented by light (needles or plates) and dark regions, respectively. The $\alpha$ phase (light region) represents a solid solution of $\mathrm{Zn}$ in $\mathrm{Cu}$ ( $\mathrm{Zn}$-rich phase) and $\mathrm{CuZn}$ intermetallic (dark region, $\mathrm{Cu}$-rich phase) ${ }^{5,22,23}$. $\mathrm{ACu}-\mathrm{Zn}$ binary alloy phase diagram is shown in Fig. 3(a) $)^{6,9,24}$. Fig. 3(b) shows the experimental cooling curves at points \#1 (top of the casting) and \#2 (at bottom). It is worth noting that all steps (procedures) applied in the investment casting were very similar in order to obtain the examined samples. The Zn content and shaped-ring of Models $1 \mathrm{~B}$ and 3 are different. It can clearly be observed that Widmanstätten (alpha-phase) structures are parallel to the $\beta(110)$ plane and it precipitates at the grain boundary (GB) of the $\beta$ phase, as well known in previous studies ${ }^{23,25-27}$.

A schematic representation to explain the precipitation and mechanism of formation for Widmanstätten structure has been recently reported ${ }^{23}$. When a Widmanstätten structure is precipitated, a tile angle is formed and this phase growths toward to Y direction, as shown in Fig. 2(a). It is known that the island structure is parallel to the acicular structure and the island transfers into the acicular structure for another section $^{23,26}$.

A mixture between needle-like Widmanstätten morphology and an island structure are observed in Fig. 2(a) and (c). The GB size is ranged between $195( \pm 15) \mu \mathrm{m}$ and the average of the width for the alpha-phase (needle-like) Widmanstätten is of about $32( \pm 12) \mu \mathrm{m}$, while their corresponding average of the length is of about $85( \pm 8) \mu \mathrm{m}$. The characterization of coarser islands is clearly observed in Fig. 2(c) and (d). It can also be said that both the average of the length and width of the microstructure shown in Fig. 2(c) and (d) are higher than other ones. Hsieh et al. ${ }^{23}$ have reported that finer (shorter) plate and acicular morphologies constitute slower mobile regions of the GB than the coarser morphology.

As aforementioned, two typical cooling curves corresponding with those thermocouples located at points \# 1 (at top of the casting) and \# 2 (at bottom), are shown in Fig. 3(b). It is remarkable that the flask is displaced inside a rotate furnace under a $0.5 \mathrm{rpm}$ and temperature setting is at $913 \mathrm{~K}$ during 8 $\mathrm{h}$ before the pouring brass molten casting. The flasks (steel carbon) were displaced with its top at bottom of the rotate base of the furnace in order to dewaxing be provided. The dewaxing is facilitated with this displacement and at point \#2 a higher temperature $\left(\sim 913 \mathrm{~K}\right.$, i.e. $\left.\sim 640{ }^{\circ} \mathrm{C}\right)$ than the point \# 1 is registered $\left(\sim 853 \mathrm{~K}\right.$, i.e. $\left.\sim 580^{\circ} \mathrm{C}\right)$.

Fig. 3(c) depicts distinctive experimented temperatures in order to evidence the thermal behavior at bottom, $1 / 2$ and $2 / 3$ from the bottom of the flask (at pattern tree). From the cooling curves, it can be observed that at bottom of the casting a temperature of about $1287 \mathrm{~K}\left(\sim 1014{ }^{\circ} \mathrm{C}\right)$ is achieved. It should be remembered that this temperature profile is attained when the brass is poured out. At the top of the casting, the temperature was recorded of about 1273 


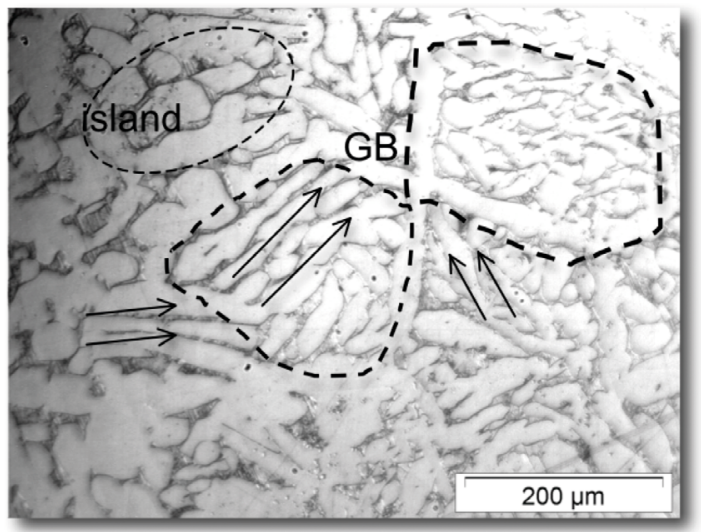

(a)

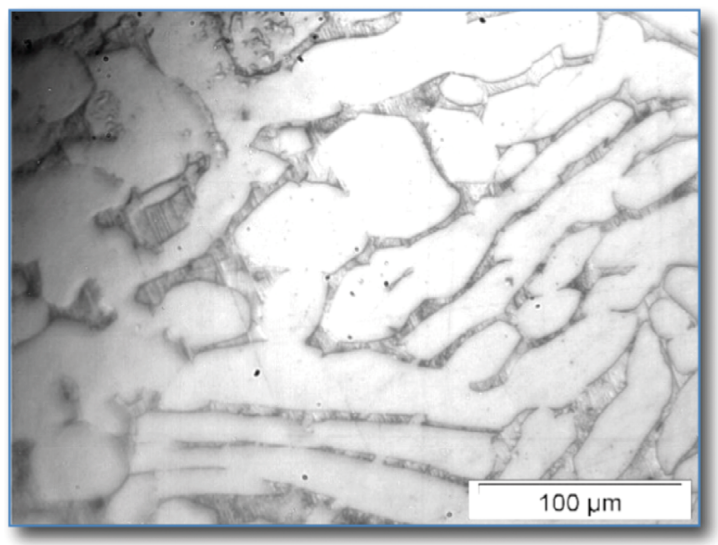

(c)

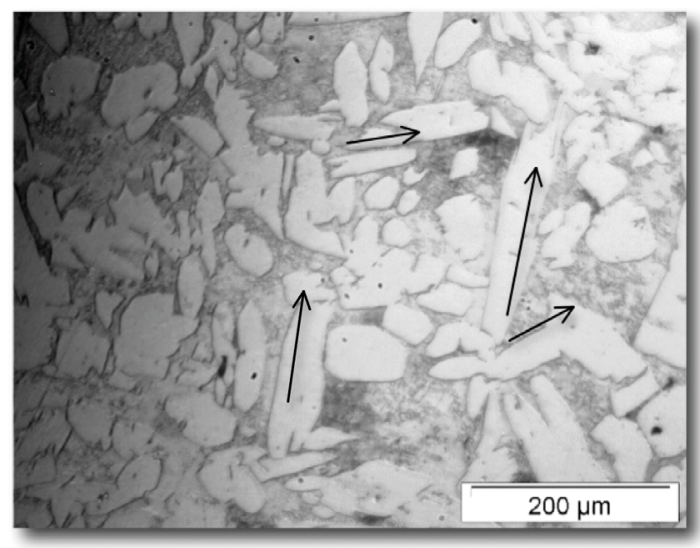

(b)

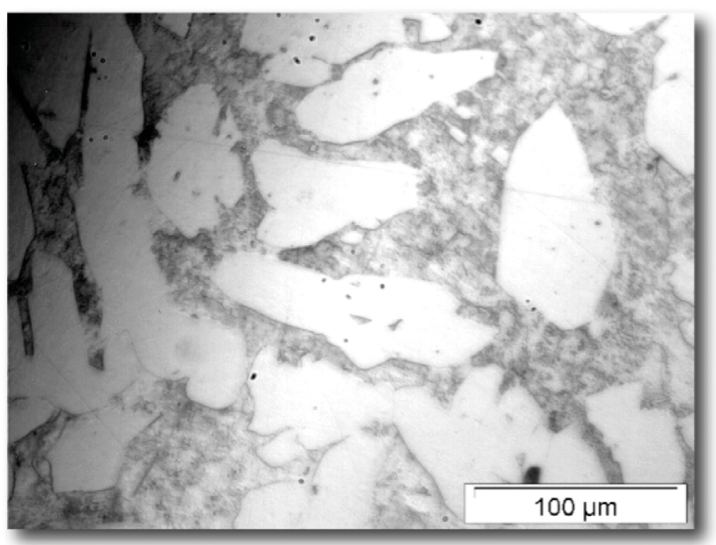

(d)

Figure 2. Typical microstructure arrays in different magnifications for brass C35ZA alloy located at: (a) and (c) point \#1 (top of the casting) and (b) and (d) point \#2 (bottom of the casting).

$\mathrm{K}\left(\sim 1000^{\circ} \mathrm{C}\right)$. It was taken of about $45 \mathrm{~s}$ and $34 \mathrm{~s}$ to initiate the solidification at positions \#2 (bottom) and \#1 (top), respectively. It is perceived that the bottom of the casting (point \#2) solidifies after the point \#1. This initiates at 1210 $\mathrm{K}\left(937{ }^{\circ} \mathrm{C}\right)$ up to $1198 \mathrm{~K}\left(925^{\circ} \mathrm{C}\right)$ under cooling rates of $0.12( \pm 0.011) \mathrm{K} / \mathrm{s}$ and $0.07( \pm 0.008) \mathrm{K} / \mathrm{s}$ at position \#2 (bottom) and \#1 (top), respectively. These cooling rates are typically observed when a ceramic (gypsum) shell mold in the investment casting is used.

Based on these aforementioned experimental results, it is corroborated with the jewelry manufacturers that commonly not check, inspect and controlling the eminent molten before pouring in chamber or mold. As will forwardly be discussed, these operational procedures have an important roles on the resulting microstructure arrays and consequently on their corresponding results of the mechanical behavior.

It is well known that in an equilibrium solidification condition, a peritectic temperature at $1175 \mathrm{~K}\left(902{ }^{\circ} \mathrm{C}\right)$ will occur, as shown in $\mathrm{Cu}-\mathrm{Zn}$ phase diagram ${ }^{28-31}$. The liquidus temperature seems to be at $1210 \mathrm{~K}\left(937^{\circ} \mathrm{C}\right)$ and the beta-phase transformation seems to be consolidated at $1148 \mathrm{~K}\left(902^{\circ} \mathrm{C}\right)$, as observed in $\mathrm{Cu}-\mathrm{Zn}$ phase diagram. At temperature $\sim 1198 \mathrm{~K}$ $\left(\sim 925^{\circ} \mathrm{C}\right)$ a slight variation in cooling curve is observed. This seems to be correlated with a modified peritectic transformation due to a non-equilibrium solidification condition. Some investigations have shown that the peritectic temperature in a non-equilibrium can slightly be varied ${ }^{28-31}$. It is remarkable that solidification in a non-equilibrium condition is typically applied in jewelry sector, which indicates that preprograming of the operational parameters have important roles onto the resulting mechanical behavior.

Investigation developed by Miettinen ${ }^{31}$ considering $\mathrm{Cu}-\mathrm{Zn}$ alloys system has demonstrated that the solidus temperature and $\alpha \rightarrow \alpha+\beta$ transformation field are significantly modified when cooling rate is increased (i.e. displaced to left side ortowards to lower $\mathrm{Zn}$ content direction). Miettinen ${ }^{31}$ has demonstrated a partial $\mathrm{Cu}-\mathrm{Zn}$ phase diagram with four variations of solvus line as a function of different cooling rates (i.e., under equilibrium, $0.1,1$, and $10^{\circ} \mathrm{C} / \mathrm{s}$ ). Considering these lines and $\mathrm{Zn}$ content (i.e. between 33 and 34 wt. \%), the transformation have occurred between 1 and $0.1 \mathrm{~K} / \mathrm{s}$. Although non-equilibrium solidification is occurred, the 

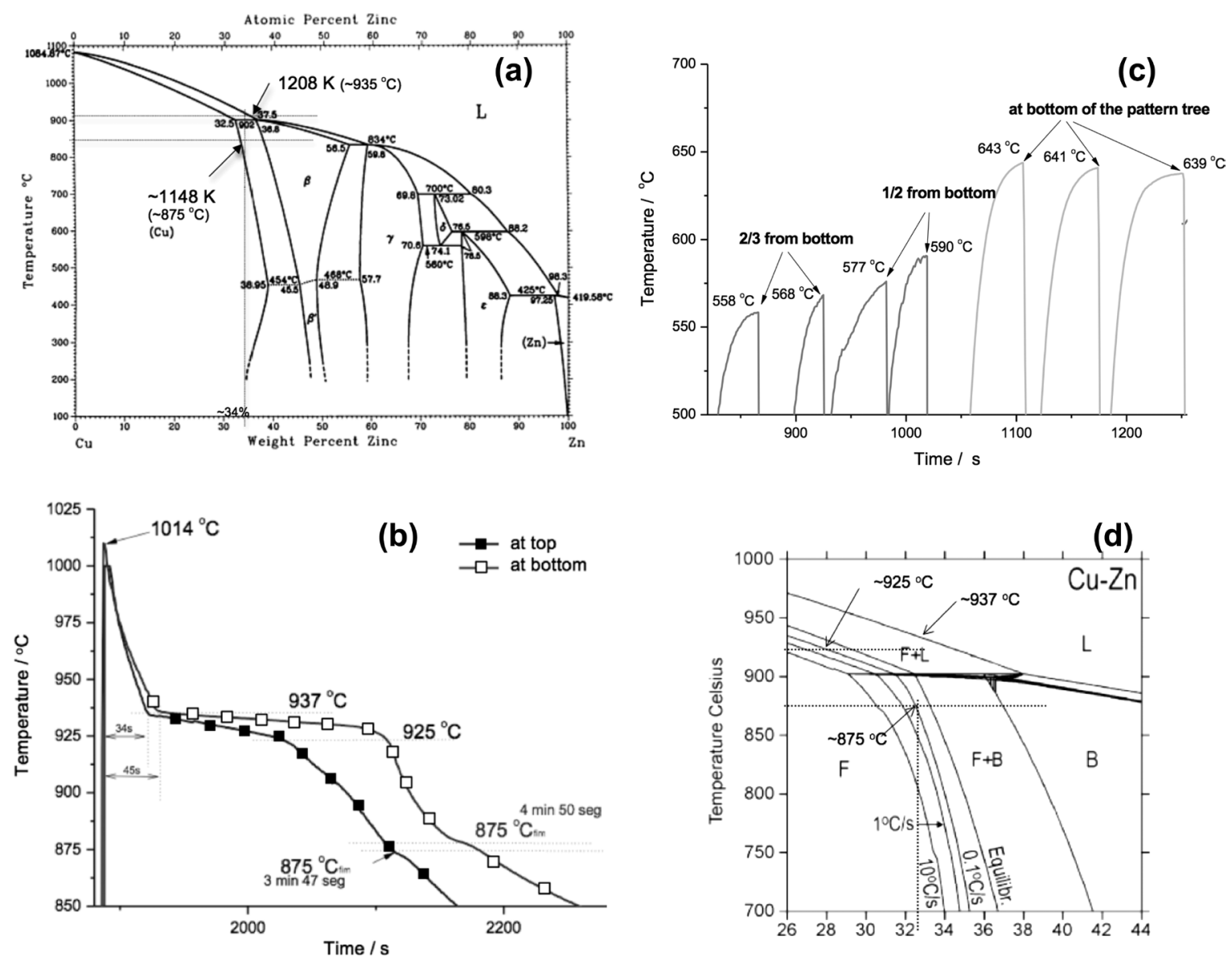

Figure 3. (a) Cu-Zn phase diagram; (b) Experimental cooling curves at points \#1 (top of the casting) and \#2 (at bottom); (c) recorded temperature in three distinct positions inside the pattern tree before the casting (i.e. at bottom, $1 / 2$ and 2/3 from the bottom of the flask); and (d) a partial $\mathrm{Cu}-\mathrm{Zn}$ phase diagram adapted from Miettinen ${ }^{31}$ evidencing the effect of cooling rate on transformation temperatures for brasses.

observed thermal transformations seem to be similar with prescribed in phase diagram, as shown in Fig. 3(d) (adapted from $\left.^{31}\right)$.

Another important observation that should also be taken in account is the fact that the piece located at bottom of the pattern casting tends to be a slightly higher $\mathrm{Cu}$ content than the sample observed at top of the casting. This is intimately associated with $\mathrm{Cu}$ segregation. It is known that $\mathrm{Cu}$ density is of about $25 \%\left(\sim 8.9 \mathrm{~g} \mathrm{~cm}^{-3}\right)$ higher than $\mathrm{Zn}(\sim 7.14 \mathrm{~g}$ $\mathrm{cm}^{-3}$ ), which under a slow solidification a $\mathrm{Cu}$ segregation is provided. Table 2 shows the XRF results (average from duplicate analysis) for the examined C35ZA samples at positions \#1 and \# 2 evidencing that $\mathrm{Cu}$ segregation has occurred. Several manufacturers reasonably neglect these thermo and physical phenomena. Consequently a rather and poorly homogenization of the melting is provided and a deleterious effect provoked by a $\mathrm{Cu}$ macrosegregation is attained. It is mentioned deleterious effect due to the difference in the $\mathrm{Cu}$-to- $\mathrm{Zn}$ mass ratio, the resulting mechanical behavior is significantly affected. With this, the hardness is decreased while the ductility is increased and a definitive plastic deformation on the surface of the pieces when polishing can easily occur. This means that a complementary treatment to correction at the surface will be demanded. Finally, the manufacturing costs can significantly be modified.

\subsection{Resulting microstructure array: distinctive Models}

A comparison of the resulting microstructure arrays between the pieces with Models 1 and 3 is shown in Fig. 4. It is remembered that Models 1 and 3 have similar $\mathrm{Zn}$ and Al contents. Although similar cooling conditions have been applied in order to produce the Models 1 and 3, it seems that due to its distinctive shapes (i.e. Model 3 is lighter and thinner than Model 1), their corresponding microstructural arrays are reasonably different. This suggests that a thermally induced microstructural modification is corroborated. It is worth noting that $\mathrm{Cu}$ segregation can significantly affect both the hardness and ductility, as aforementioned. The measured weights of the Models 1 and 3 are of about $48( \pm 4)$ and $14( \pm 2) \mathrm{g}$, respectively. This demonstrates that for a tree casting containing a Model 3, their corresponding cooling rate will be higher than the Model 1. It is remarkable that similar pouring temperatures were adopted. 
Table 2. Experimental XRF results of the examined C35ZA samples at positions \#1 and \# 2.

\begin{tabular}{cccccccc}
\hline \multicolumn{7}{c}{ Chemical Composition (wt. \%) } \\
\hline Cu & Zn & Al & Si & Sn & Pb & Fe \\
\hline C35ZA point \#1 & $64.34( \pm 0.5)$ & $34.31( \pm 0.6)$ & $1.29( \pm 0.1)$ & $<0.02( \pm 0.001)$ & $<0.01( \pm 0.001)$ & N/A & $<0.02( \pm 0.001)$ \\
C35ZA point \#2 & $67.96( \pm 0.8)$ & $30.84( \pm 0.6)$ & $1.13( \pm 0.1)$ & $<0.02( \pm 0.001)$ & $<0.02( \pm 0.001)$ & N/A & $<0.02( \pm 0.001)$ \\
\hline
\end{tabular}

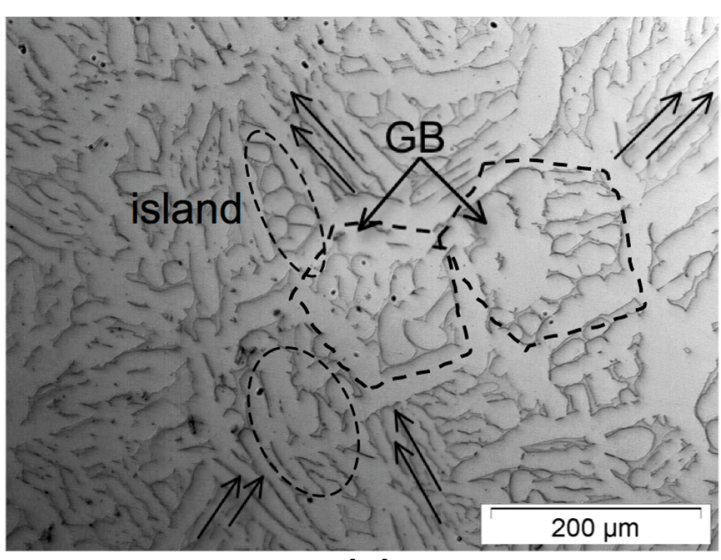

(a)

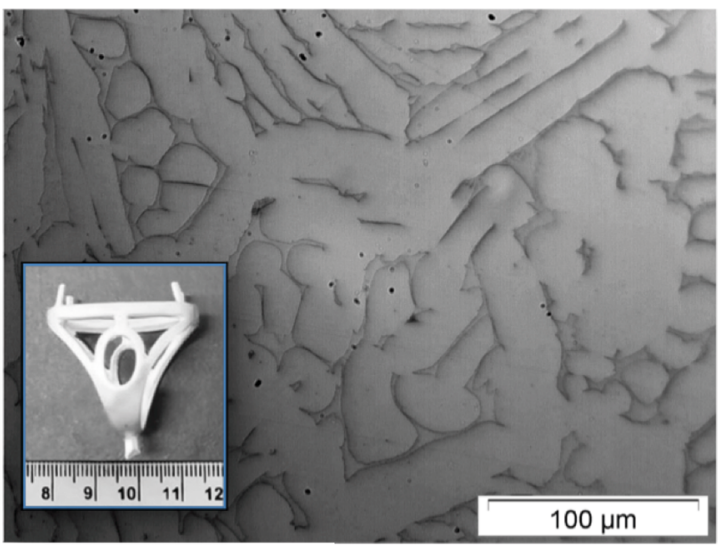

(c)

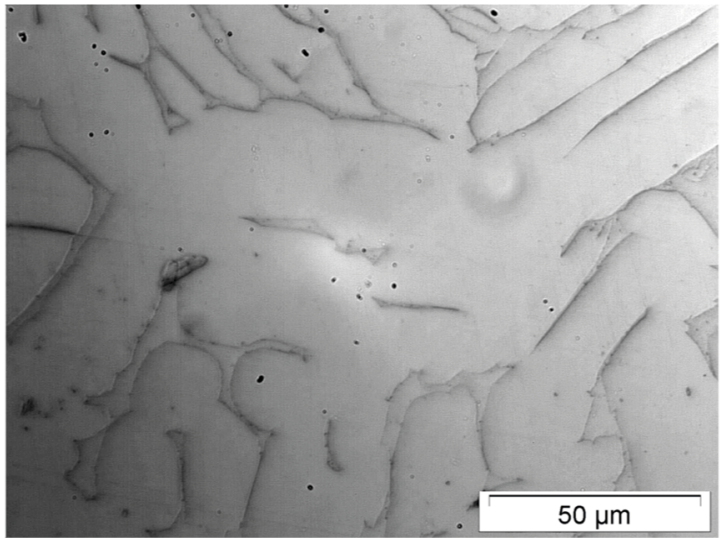

(e)

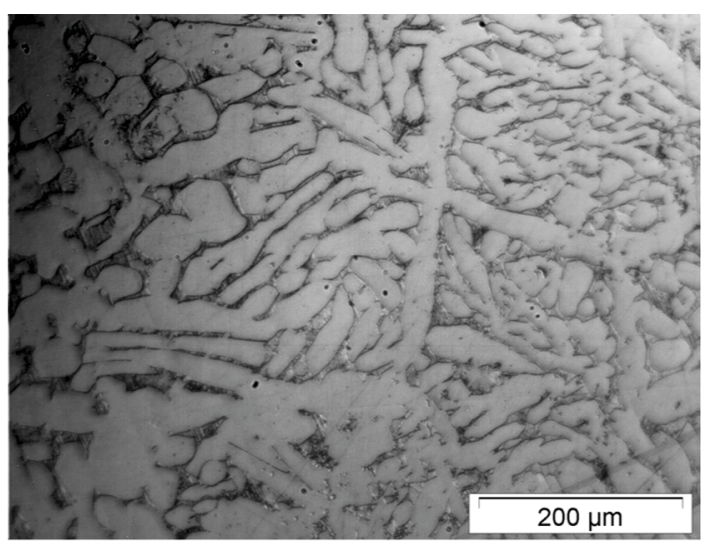

(b)

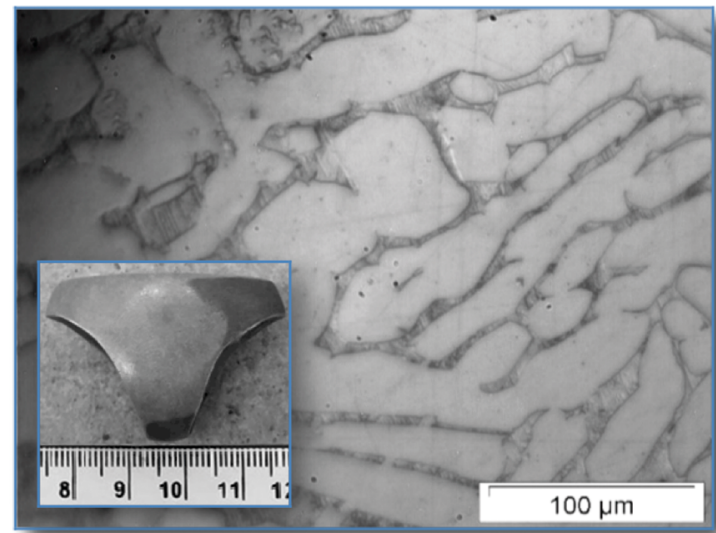

(d)

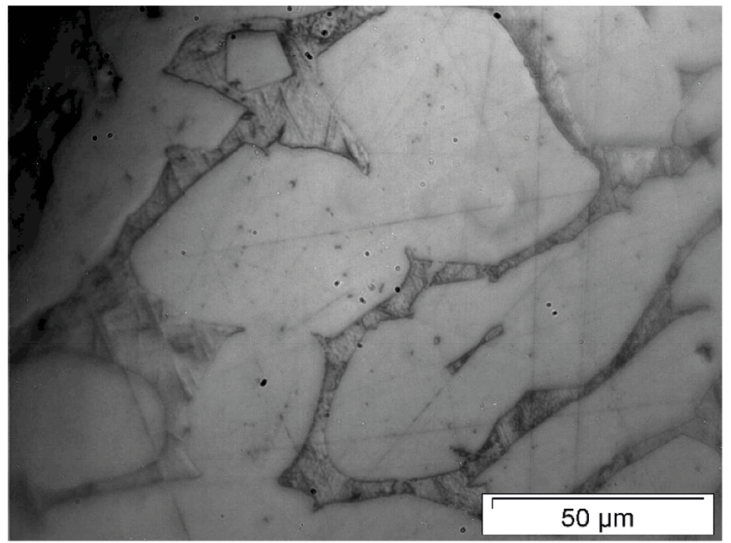

(f)

Figure 4. Typical microstructure arrays in different magnifications for brass C35ZA considering distinctive model pieces: (a), (c) and (e) Model 3 (inside Fig. 4c) and (b), (d) and (f) Model 1 (inside Fig. 4d). 

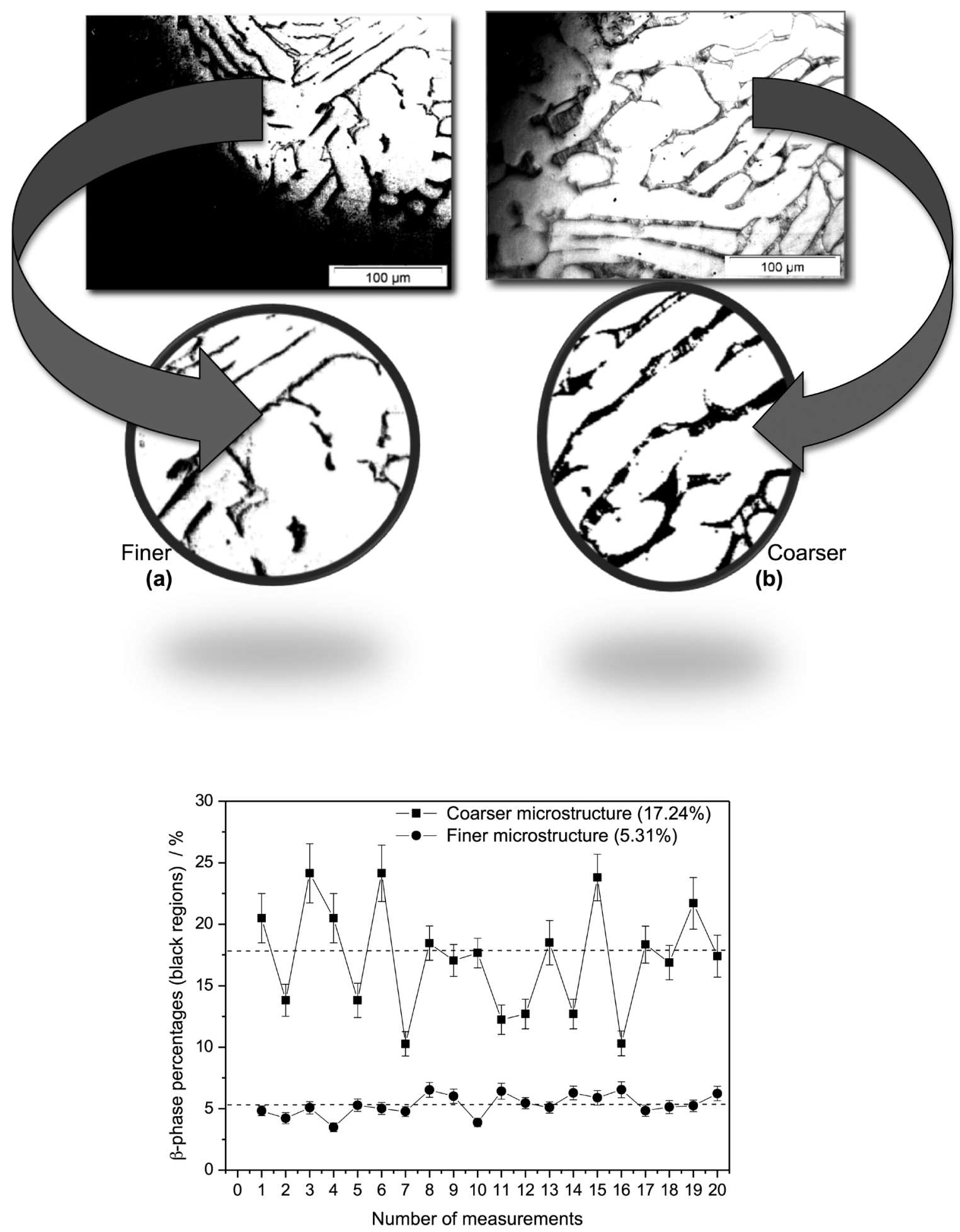

(c)

Figure 5. (a) and (b) Binary images from those micrographs shown in Fig. 6, and (c) the average of the $\beta$-phase determined from the binary images. 
It is also clearly observed the typical Widmanstätten structures for both the Models 1 and 3 (thinner) are formed. The former microstructural array (Fig. $6 \mathrm{~b}$, $\mathrm{d}$ and $\mathrm{f}$ ) is coarser than the latter (Fig. 6 a, c, and e). With this comparison, it can be induced that the thinner Model has a finer needle-like $\alpha$ phase, finer grain size and islands than ones.

Fig. 2(a) and (c) corresponds to the solidified microstructural array at point $\# 1$, which is located at the top of the casting. On the other hand, the resulting microstructure of the C35ZA alloy is correlated with the bottom of the casting (pattern tree), as shown in Fig. 2(b) and (d). Based on these microstructural observations, it can be seen that a typical and traditional Widmanstätten structure is formed. The needle-like $\alpha$-phase Widmanstäetten for the Model 3 (thinner) attains a width between 12 and $50 \mu \mathrm{m}$ while the Model 1 has attained between 25 and $80 \mu \mathrm{m}$, as shown in Figs. 4 (e) and (f). It is important to remember that a Widmanstätten structure is constituted from the precipitation of a new solid phase at high temperature decomposing into two solid phases at a lower temperature ${ }^{32}$. This precipitation usually occurs at the grain boundaries of the initial crystals within the grains themselves (needle- or plate-like phase), which have particular orientations depending on the crystallographic structures of the original crystals ${ }^{32}$.

It is known that a $\beta$-phase ( $\mathrm{Zn}$-rich region, dark region) has a body centered cubic (BCC) lattice ${ }^{32-34}$, which is harder than the $\alpha$-phase. $\mathrm{Cu}$ has a face-centered cubic (FCC), while a hexagonal close-packed lattice (HPC) is constituted by $\mathrm{Zn}$. After a peritectic reaction, the $\mathrm{Zn}$-rich phase ( $\beta$-phase) is consolidated. These phases are constituted by dark regions, as shown in Figs. 2 and 4. For this reason, a high cooling rate induces to a finer microstructural array. This provides a finely and homogeneously distributed $\beta$-phase, which provides for the Model 3 a microstructure of about $3 \mathrm{x}$ finer then other examined samples. This also suggests that the mechanical behavior is improved. When the ductility is predominantly desired in a component produced under this condition, the thermal condition should be revised in order to preprogram another more adequate. Although very similar $\mathrm{Cu}$ and $\mathrm{Zn}$ contents, the finer microstructure (Model 3) has $\sim 5 \%$ of the average of the black area percentage corresponding with $\beta$-phase, while $\sim 17 \%$ corresponding with coarser microstructure is attained, as shown in Fig. 5.

Fig. 5(a) and (b) demonstrates typical binary images of those micrographs shown in Fig. 4. Image intensity threshold was applied in order to become binary images using sections of 300 per 300 pixels (at least $100,000 \mu \mathrm{m}^{2}$ ). Fig. 5(c) shows the average of the $\beta$-phase determined from the obtained binary images. It is known that the $\beta$-phase is primarily solidified, and this confirms that a high cooling rate provides finely and homogeneously distributed black regions. On the other hand, a more slowly cooled microstructure is constituted by a coarser $\beta$-phase and needle to plate-like $\alpha$-phase (Widmanstätten structure). It is also worth noting that the jewelry manufacturers immerse the brass casting into water container intending to reduce the producing cycle. Consequently, distinct microstructural array from that initially planned are established. Instead a reduction of the production time be attained, the complementary procedures will be required, and consequently the final cost will be increased.

\subsection{Resulting microstructure array: two distinctive Zn contents}

In order to evaluate the effect of the chemical modification on the resulting microstructure array of the examined brasses, the Model 1 was selected. However, $\mathrm{Zn}$ content was reduced to $\sim 30$ wt. $\%$ and $\sim 1.6 \%$ (wt. $\%$ ) and $\mathrm{Al}$ content was remained. This sample was called as $\mathrm{Cu}-30$ wt. \% Zn alloy with $~ 1.6$ wt. \% $\mathrm{Al}(\mathrm{C} 30 \mathrm{ZA})$ considering the Model 1B, as shown in Fig. 1(b).

Fig. 6 shows the distinct optical magnifications for a typical microstructure of a C30ZA. A duplex $\alpha / \beta$ phase formation is clearly observed. For this brass composition, the Widmanstätten morphology was not characterized. The $\alpha$-phase (light region) is predominantly formed, while the $\beta$ phase (dark region) seems to be occupied into pseudointerdendritic arms. Experimental Investigations ${ }^{22,23}$ have shown similar microstructures when $\mathrm{Zn}$ content attains between 30 and 40 wt. \%. It is important to remember that this microstructure shown in Fig. 6 was manufactured by using the same Model 1 shown in Fig. 1(b). Based on literature, it is presumed ${ }^{23,26-31}$ that a Widmanstätten array in a brass has a critical chemical composition ( 30 wt. $\%$ $\mathrm{Zn}$ ) to be formed. Depending of the applied cooling rate, the composition $v$ s. temperature for $\alpha+\beta$ phase and Widmanstätten formation can be significantly modified ${ }^{31}$. This seems to help to explain the reason for a sample C30ZA be constituted by a duplex structure formation. In the investigation developed by Pantazopoulos and Vazdirvanidis ${ }^{22}$, it was found that the brass phases formation are intimately associated with both the casting and thermo-mechanical conditions (e.g. cooling rate and extrusion temperature, respectively).

Although Widmanstätten structure is not predominantly characterized, it seems that both $\mathrm{Zn}$ content and cooling rate have corroborated to initiate this formation, as depicted in Fig. 6. Although the cooling rate was no specifically determined for this samples, it will define both the alpha and $\alpha$ and $\beta$ phase morphologies and sizes. Wood and Hellawell ${ }^{26}$ have demonstrated that $\alpha$-phase precipitates in distinctive morphologies, which are firstly occurred at boundaries and from $\beta$-phase, as shown in Fig. 6 (d). The results of EDS patterns of the C35ZA and C30ZA brasses samples are shown Fig. 6 (e). Al content in the examined alloys is detected. It can also be reported that into the jewelry sector, the manufacturers have commonly added Al contents higher than $1 \mathrm{wt} \%$. This significantly affects the resulting microstructure without improvement into the mechanical behavior. This based on the fact that its commonly pouring temperature 


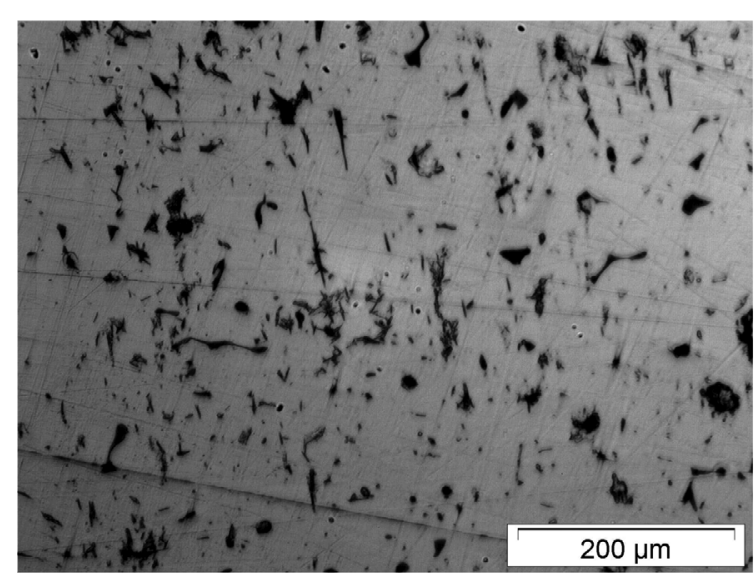

(a)

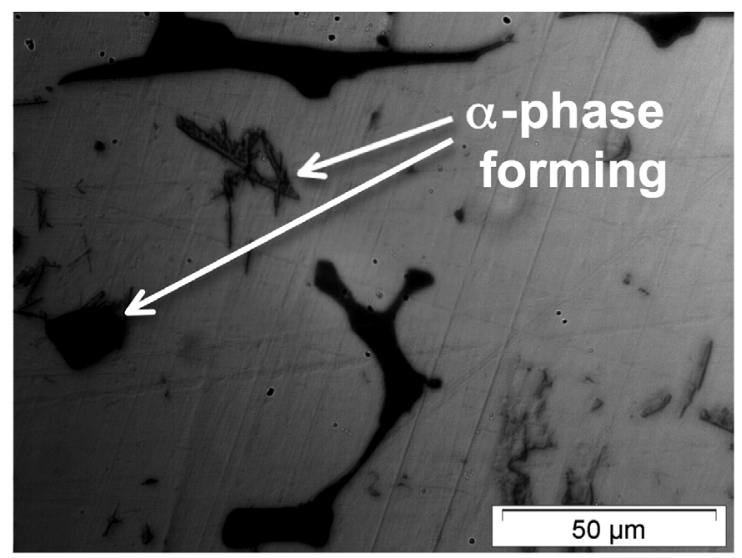

(c)

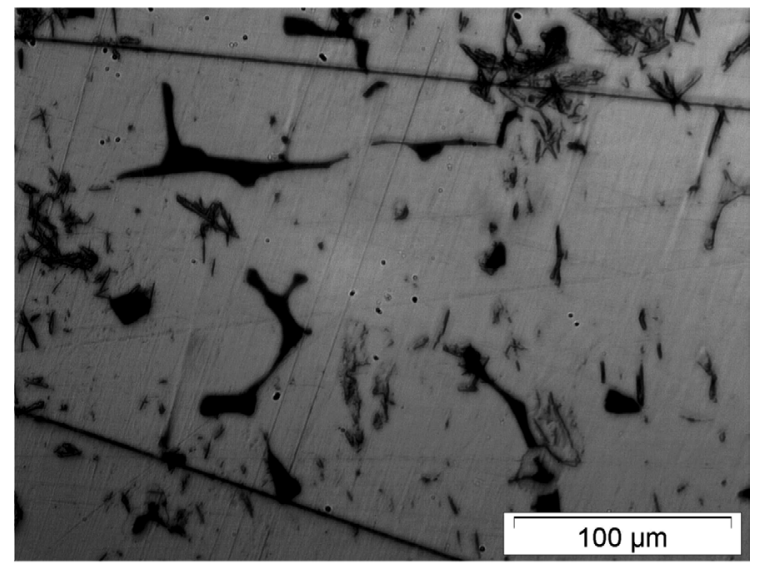

(b)

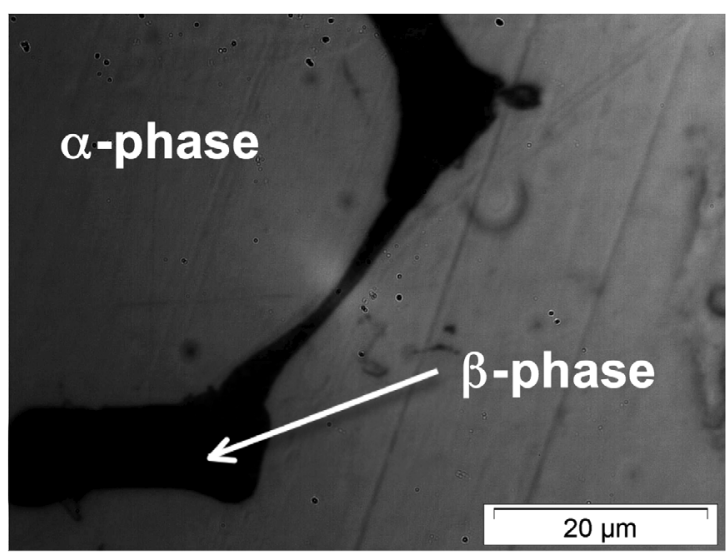

(d)

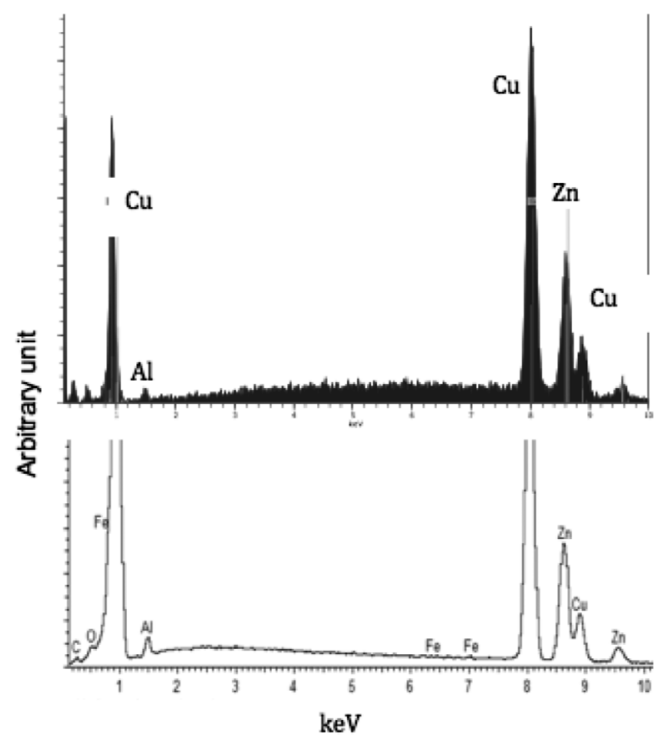

(e)

Figure 6. Distinctive optical magnifications of the microstructure arrays of a C30ZA brass sample: (a) 50x, (b) 100x, (c) 200x, (d) 1000x, and (e) EDS results of the C35ZA and the C30ZA brasses. 
is relative higher than a certain adequate temperature and both $\mathrm{Zn}$ and $\mathrm{Al}$ contents can be "missed". This is strongly affected when the cooling rate and/or Zn content (or Cu-to-Zn ratio) are modified. Besides, $\mathrm{Al}$ addition seems to provide a deleterious effect in the gold plating, which delaminates the Au-plated coating. Besides, dirt into galvanic bath can also be incorporated and the efficiency of the gold-plating and its cycling life-time are considerably be reduced.

From the metallurgical point of view, thermally and chemically induced modifications have affected the resulting microstructure of the examined brasses. Different hardness measures have been obtained due to these distinct microstructural morphologies. In order to correlate the experimental hardness results with their corresponding microstructure array some comparisons were made.

\subsection{Hardness, microstructure array and cooling rate correlations}

It was previously mentioned that $\mathrm{HPC}$ and $\mathrm{FCC}$ lattices are corresponding with $\mathrm{Zn}$ and $\mathrm{Cu}$, while a $\mathrm{BCC}$ lattice characterizes the $\beta$ - $\mathrm{Zn}$ rich phase ${ }^{32-34}$. Haque and $\mathrm{Khan}^{35}$ have reported that a $\mathrm{Cu}-\mathrm{Zn}$ casting alloy has both its hardness and tensile strength varying with the imposed casting condition. It was reported that the sand casting samples attain hardness values $\sim 45 \mathrm{HV}$, while the chilled casting samples have achieved of about $60 \mathrm{HV}$. The former alloy sample evidences a tensile strength $\sim 150 \mathrm{MPa}$, while the latter has exhibited approximately $200 \mathrm{MPa}$. It is important to remember that the resulting microstructure characterized in this mentioned investigation has no demonstrated a Widmanstätten formation. This seems to be intimately correlated with their chemical composition, i.e. $\sim 69$ wt. $\% \mathrm{Cu}, 30 \%$ wt. $\mathrm{Zn}, 1.2$ wt. $\% \mathrm{Sn}$ and $0.11 \mathrm{wt} . \% \mathrm{~Pb}^{35}$.

In order to compare the hardness of the examined brasses in this present investigation and to correlate with their resulting microstructures, the hardness measurements of commercial brasses are also discussed. Based on the mechanical behavior results obtained from the Copper Development Association ${ }^{36,37}$, two casting brasses commercially recognized into Unified Numbering System were analyzed, i.e. (UNS) C85500 (casting) and C85450. Since these mentioned UNS brasses have similar chemical compositions with those examined in this present study (i.e. $\mathrm{Zn}$ content, low or free- $\mathrm{Pb}$ and $\mathrm{Sn}$, and low $\mathrm{Fe}$ and $\mathrm{Al}$ contents), they were selected in order to comparison be provided. In this sense, the mechanical strengths of both commercial and examined brasses are shown in Table 3. Although the corresponding cooling rates for commercial brasses are not indicated (no described in literature), it is induced that the $\mathrm{C} 85500$ produced using a permanent mold surely has a higher cooling rate than the C85500 produced by using a sand-cast condition. This significantly affects their hardness (in HRB or $\mathrm{H}$ Brinell) and tensile strength, as demonstrated in Table 3.
Based on the experimental hardness results and compared with the aforementioned commercial brasses, it is hardly induced that the increase of the hardness of a duplex brass component produced by investment casting is obtained when the cooling rate receives a certain preprograming and controlling. A C35ZA brass sample constituting the Model 3 (Fig. 1c) produced under a cooling rate $\sim 0.18 \mathrm{~K} / \mathrm{s}$ generates a finely and homogeneously Widmanstätten microstructure array. Their obtained hardness result $(\sim 88 \mathrm{HB})$ is similar to those obtained for commercial casting brasses $(\sim 85 \mathrm{HB})^{36,37}$.

Based on these hardness measures and the obtained microstructural arrays, it can also be concluded that the highest Brinell hardness is that of the sample with $\sim 35 \mathrm{wt}$. $\% \mathrm{Zn}$ and $1.5( \pm 0.1)$ wt. \% $\mathrm{Al}$ contents, which has been produced under a $0.18 \mathrm{~K} / \mathrm{s}$. The intermediate $\mathrm{HB}$ hardness is that of similar chemical composition under $0.12 \mathrm{~K} / \mathrm{s}$. The lowest $\mathrm{HB}$ hardness values are those of the C35ZA and C30ZA brasses samples.

Although the experimental cooling rate was not determined for the C30ZA sample, it is speculated that their corresponding cooling rate is similar to $\mathrm{C} 35 \mathrm{ZA}($ i.e. $\sim 0.07 \mathrm{~K} / \mathrm{s})$ due to their shape is also very similar. It is expected that this similarity in hardness is associated with duplex structure formation. It is clearly also observed that $\mathrm{HV}$ microhardness measurements have also accompanied the general HB hardness, i.e. HV microhardness decreases with decreasing the cooling rate.

A number of experimental investigations ${ }^{38-44}$ considering distinctive materials and alloys has reported that the increase of the imposed cooling rate generates an increase in the mechanical behavior. Based on the experimental results and comparing with commercial brasses, evaluations between examined brasses and those commercial brasses can be carried out. The effect of the cooling rate on the resulting microstructure array is summarized in Table 3. Since the main core of this proposed investigation is to demonstrate the effect cooling rate upon the microstructure and consequently on the attained hardness, when comparing the values shown in Table this correlation can be understood. It is also worth noting that a duplex brass has both the alpha and betha phases. These phases have their individual contribution in order compose the general hardness of the solidified brass. As also can be observed in Table 3, the $\alpha$-phase has a lower hardness (designated in $\mathrm{HV}$ hardness) than the $\beta$-phase. It is confirmed that $\beta$-phase is hardener than $\alpha$-phase, as also shown in Table 3. This helps to explain the fact when a fine and homogenously $\beta$-phase distributed induces to a positive strengthening effect.

The correlations between the experimental results for Brinell hardness (HB) and the cooling rate of both the C35ZA and C30ZA brasses samples and their corresponding microstructural arrays are summarized in Fig. 7. A first analysis indicates that similar cooling rate (between 0.04 and $0.07 \mathrm{~K} / \mathrm{s}$ ) applied to two distinctive $\mathrm{Zn}$ contents (i.e. 30 and 35 wt. \%) induces to an equivalent mechanical 
Table 3. Mechanical properties* of both the commercial and examined $\mathrm{Cu}-\mathrm{Zn}$ brasses.

\begin{tabular}{|c|c|c|c|c|c|c|}
\hline & $\begin{array}{l}\text { Casting } \\
\text { Condition }\end{array}$ & Designation & $\begin{array}{l}\text { Cooling } \\
\text { rate }\end{array}$ & Hardness & Tensile Strength & Microstructure \\
\hline \multirow{3}{*}{ Commercial } & Permanent mold & $\mathrm{C} 85500^{* *}$ & N/A & $55 \mathrm{HRB}(\sim 85 \mathrm{HB})$ & $60 \mathrm{ksi}(\sim 420 \mathrm{MPa})$ & N/A \\
\hline & Sand cast & $\mathrm{C} 85500^{* *}$ & N/A & $53 \mathrm{HRB}(\sim 82 \mathrm{HB})^{* * *}$ & $54 \mathrm{ksi}(\sim 370 \mathrm{MPa})$ & N/A \\
\hline & N/A (rod \& bar) & C85450 & N/A & $80 \mathrm{HRB}(\sim 120 \mathrm{HB}) * * *$ & $55 \mathrm{ksi}(\sim 375 \mathrm{MPa})$ & N/A \\
\hline \multirow{4}{*}{ Examined } & \multirow{4}{*}{$\begin{array}{l}\text { Investment } \\
\text { casting }\end{array}$} & $\begin{array}{l}\text { C35ZA } \\
\text { (Model 1) }\end{array}$ & $0.12 \mathrm{~K} / \mathrm{s}$ & $\begin{array}{c}71( \pm 2) \mathrm{HB} \\
115( \pm 8) \mathrm{HV} \text { at } \beta \text { phase; } \\
60( \pm 4) \mathrm{HV} \text { at } \alpha \text { phase }\end{array}$ & \multirow{4}{*}{ N/A } & $\begin{array}{c}\alpha+\beta \text { phases } \\
\text { (needle-like } \\
\text { Widmanstätten) }\end{array}$ \\
\hline & & $\begin{array}{c}\text { C35ZA } \\
\text { (Model 2) }\end{array}$ & $0.07 \mathrm{~K} / \mathrm{s}$ & $\begin{array}{c}60( \pm 2) \mathrm{HB} \\
90( \pm 10) \mathrm{HV} \text { at } \beta \text { phase; } \\
60( \pm 5) \mathrm{HV} \text { at } \alpha \text { phase }\end{array}$ & & $\begin{array}{c}\alpha+\beta \text { phases } \\
\text { (coarser Widmanstätten) }\end{array}$ \\
\hline & & $\begin{array}{c}\text { C35ZA } \\
\text { (Model 3) }\end{array}$ & $0.18 \mathrm{~K} / \mathrm{s}$ & $\begin{array}{c}88( \pm 2) \mathrm{HB} \\
124( \pm 4) \mathrm{HV} \text { at } \beta \text { phase; } \\
70( \pm 5) \mathrm{HV} \text { at } \alpha \text { phase }\end{array}$ & & $\begin{array}{c}\alpha+\beta \text { phases } \\
\text { (finer Widmanstätten) }\end{array}$ \\
\hline & & $\begin{array}{c}\text { C30ZA } \\
\text { (Model 1B) }\end{array}$ & N/A & $58( \pm 2) \mathrm{HB}$ & & $\alpha+\beta$ phases \\
\hline
\end{tabular}

*Measurements determined at environmental temperature. ** Obtained from References ${ }^{35-37}$.*** approximately converted values (ASTM E140). N/A is not available.

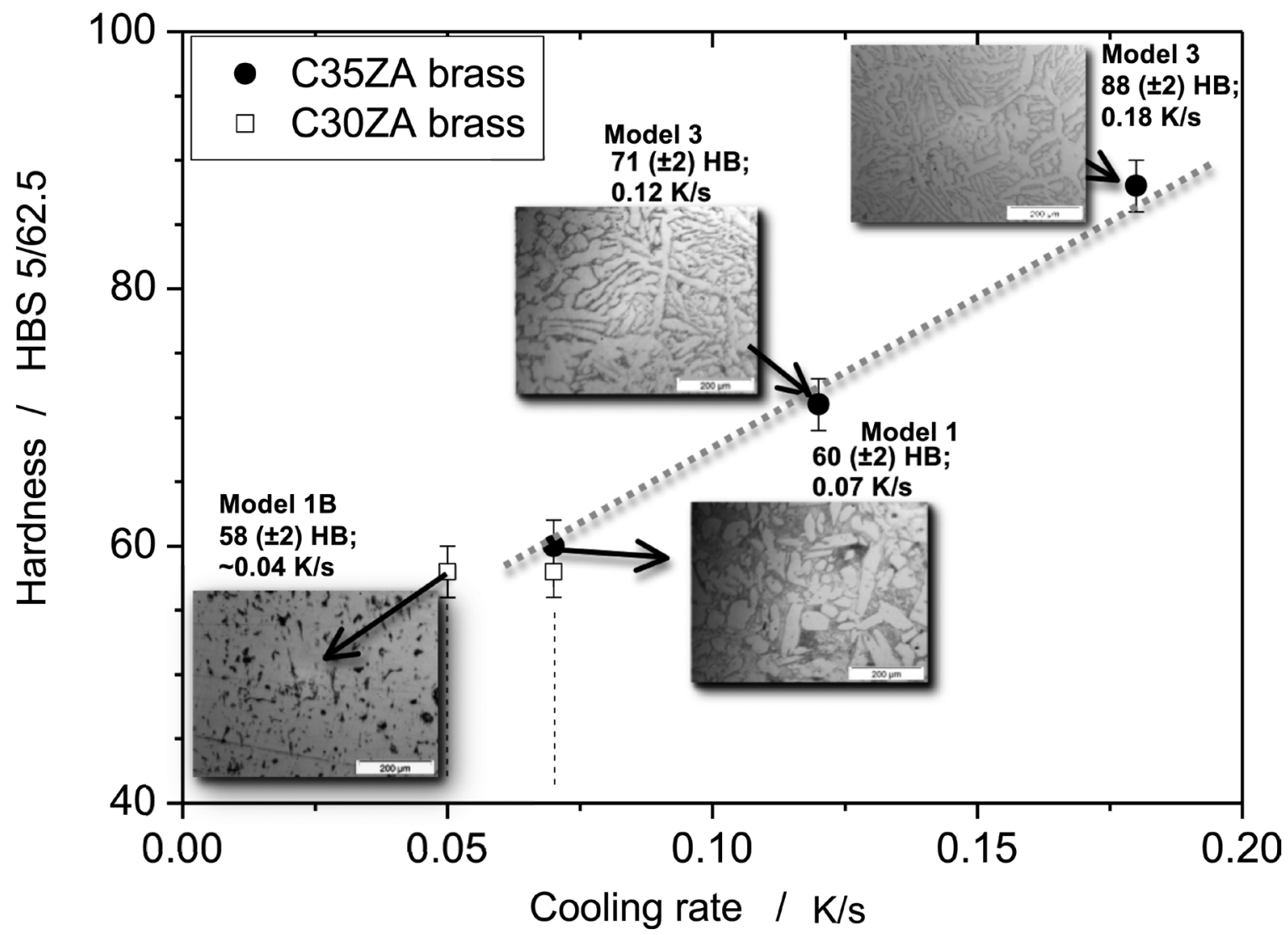

Figure 7. Correlation between experimental hardness (HB) with cooling rate for the C35ZA and C30ZA brasses.

behavior (i.e. $\sim 60 \mathrm{HB})$. On the other hand, considering a same $\mathrm{Zn}$ content, an increase of the hardness $(\sim 90 \mathrm{HB})$ is attained when a cooling rate from $\sim 0.12 \mathrm{~K} / \mathrm{s}$ to $\sim 0.2 \mathrm{~K} / \mathrm{s}$ is increased. It is remembered that the increase of about 2 times of the applied cooling rate seems to be cheaper than the increase of $\mathrm{Zn}$ content or other strengthening element addition. Besides, it should also be remembered that the addition of other elements induces to a possible inclusion of dirty into the galvanic bath. It is declared that the gold-plating is commonly carried out in different industry, which has produced the as-cast component. However, it is also believed that additional costs will be introduced to this foundry industry. 
From the aforementioned discussion concerning to the microstructural array, chemical composition and hardness measurements, it is induced that from those examined duplex brasses samples, the $\beta$ phase seems to be precipitated with $\mathrm{Al}$ content, as also verified in previous investigations s,6,22,23,26-28 $^{\text {. }}$

The Widmanstätten formation seems to be associated with both $\mathrm{Zn}$ and $\mathrm{Al}$ contents (or their $\mathrm{Zn}$ to $\mathrm{Al}$ mass ratio) and the imposed (experimentally practicable) cooling rate. For instance, the C30ZA brass sample has Al content and Widmanstätten has no occurred or no predominantly formed, as shown in Fig. 6.

Among the examined duplex brass structures, independently of their chemical composition, the hardness has increased with increasing the resulting cooling rate. This seems to be intimately associated with fineness of the resulting Widmanstätten array. This evidences that thermally and chemically induced microstructural modification affects substantially the resulting hardness. In this sense, it is hardly indicated to the jewelry's manufacturers that independently of the selected manufacturing route, the imposed cooling rate should meticulously be preprogrammed, controlled and analyzed.

In the investment casting commonly used in jewelry sector, the position (location) of the piece in the pattern tree (along the casting) should be carefully designed (planned) intending that a certain and adequate cooling rate condition be provided. This will surely originates in a microstructural array with a slightly increase in the desired mechanical behavior. For instance, if there is a design for a thinner piece to be produced (inside casting mold), a low hardness will be attained when this piece at the bottom of the casting is located (positioned). On the other hand, if an increase in the hardness is desired for this mentioned piece, it seems that the increase of the $\mathrm{Zn}$ content limiting up to $45 \mathrm{wt}$. \% is a reasonable mechanical solution. When complementary working is required (e.g. drilling, ground, polishing, etc.), it is suggested that a lower hardness be obtained. In this sense, it seems that an argon injection and/or an overheating provide a resulting ductility compatible with proposed future working. It is worth noting that the flask temperature has also an important role on the resulting microstructural array and due to, it should also be associated with the pouring temperature in order to determine the cooling rate of the examined brasses.

Based on the aforementioned experimental results associated with the fact that examined brasses have friendlyenvironmentally aspect, low relative cost associated with controllable performance (e.g. hardness, ductility, and castability), this experimental study corroborates with both jewelry and other industries in order to improve the technical and operational understanding of the effects correlated with thermal and compositional aspects and operational parameters controlling the microstructure formed. As a direct consequence, each distinctive component accordingly with their different desired performance can be appropriately preprogramed. With this, both the chemical composition ( $\mathrm{Zn}$ and $\mathrm{Cu}$ contents) and applied cooling rates before neglected by jewelry manufacturers when planning a component will be more adequately analyzed.

\section{Conclusions}

1. Based on the experimental results is revealed both thermal and chemical effects on induced microstructural modification and, consequently on the mechanical behavior. The following conclusions can be drawn.

2. Considering an investment casting proceeding and inside a same pattern tree, it is found that the manufactured components located at distinctive positions along the casting containing very similar $\mathrm{Zn}$ and $\mathrm{Al}$ contents have their values of hardness differently ranged. It is found $\mathrm{Cu}$ segregation at the bottom of the examined casting. A finer microstructure array is formed and a hardness $\sim 20 \%$ higher $(\sim 70$ HB) than the located at the bottom of the casting is provided.

3. It is also found that a thinner piece exhibits a more finely and homogeneously distributed $\beta$ phase with finer Widmanstätten structure than the piece solidified under low cooling rate. This also evidences the important role of the thermal effect on the microstructural morphology and hardness.

4. A duplex brass seems to be intimately associated with $\mathrm{Al}$ content, which induces to a strengthening effect. The hardness is increased with the increase of the cooling rate, which seems to be associated with fineness of the Widmanstätten array.

\section{Acknowledgements}

The authors acknowledge financial support provided by FAEPEX-UNICAMP (\#2335/17), and CNPq (The Brazilian Research Council, Grants \#304950/2017-3 and \#446797/2014-6).

\section{References}

1. Heidarzadeh A, Saeid T. A comparative study of microstructure and mechanical properties between friction stir welded single and double phase brass alloys. Materials Science and Engineering: A. 2016;649:349-358.

2. Dasharath SM, Mula S. Mechanical properties and fracture mechanisms of ultrafine grained $\mathrm{Cu}-9.6 \% \mathrm{Zn}$ alloy processed by multiaxial cryoforging. Materials Science and Engineering: A. 2016;675:403-414.

3. Leinenbach C, Transchel R, Gorgievski K, Kuster F, Elsener HR, Wegener K. Microstructure and Mechanical Performance of $\mathrm{Cu}-\mathrm{Sn}$-Ti-Based Active Braze Alloy Containing In Situ Formed 
Nano-Sized TiC Particles. Journal of Materials Engineering and Performance. 2015;24(5):2042-2050.

4. Zuo X, Zhu J, An B, Han K, Li R, Wang E. Influence of Fe addition on microstructure and properties of $\mathrm{Cu}-\mathrm{Ag}$ composite. Metals and Materials International. 2017;23(5):974-983.

5. Panagopoulos CN, Georgiou EP, Simeonidis K. Lubricated wear behavior of leaded $\alpha+\beta$ brass. Tribology International. 2012;50:1-5.

6. García P, Rivera S, Palacios M, Belzunce J. Comparative study of the parameters influencing the machinability of leaded brasses. Engineering Failure Analysis. 2010;17(4):771-776.

7. Sundberg M, Sundberg R, Hogmark S, Otterberg R, Lehtinen B, Hörnström SE, et al. Metallographic aspects on wear of special brass. Wear. 1987;115(1-2):151-165.

8. Mindivan H, Cimenoglu H, Kayali ES. Microstructures and wear properties of brass synchroniser rings. Wear. 2003;254(56):532-537.

9. Gierlotka W, Chen S. Thermodynamic descriptions of the $\mathrm{Cu}-\mathrm{Zn}$ system. Journal of Materials Research. 2008;23(1):258-263.

10. Ozgowicz W, Kalinowska-Ozgowicz E, Grzegorczyk B. The microstructure and mechanical properties of the alloy $\mathrm{CuZn} 30$ after recrystallizion annealing. Journal of Achievements in Materials and Manufactoring Engineering. 2010;40(1):15-24.

11. Ott D, Raub CJ. Investment casting of gold jewellery. The surface properties of castings: Effects of casting atmospheres and other factors. Gold Bulletin. 1985;18(4):140-143.

12. Raub CJ, Ott D. Gold casting alloys. The effect of zinc additions on their behaviour. Gold Bulletin. 1983;16(2):46-51.

13. Ott D, Raub CJ. Investment casting of gold jewellery. Factors affecting the filling of moulds. Gold Bulletin. 1986;19(2):34-39.

14. Nielsen JP. Solidification fundamentals of jewelry and dental casting. In: Proceedings of the Sixth International Precious Metals Institute Conference; 1982 Jun 7-11; Newport Beach, CA, USA.

15. Ingo GM, Chiozzini G, Faccenda V, Bemporad E, Riccucci C. Thermal and microchemical characterisations of $\mathrm{CaSO}_{4}-\mathrm{SiO}_{2}$ investment materials for casting jewellery alloys. Thermochimica Acta. 1998;321(1-2):175-183.

16. Sbornicchia P, Montesperelli G, Ingo GM, Gusmano G. Advances in jewellery microcasting. Thermochimica Acta. 2004;419(12):195-204.

17. Pattnaik S, Karunakar DB, Jha PK. Developments in investment casting process - A review. Journal of Materials Processing Technology. 2012;212(11):2332-2348.

18. Jiang W, Fan Z, Liao D, Dong X, Zhao Z. A new shell casting process based on expendable pattern with vacuum and lowpressure casting for aluminum and magnesium alloys. The International Journal of Advanced Manufacturing Technology. 2010;51(1-4):25-34.

19. Beeley PR, Smart RF, eds. Investment Casting. ${ }^{\text {st }}$ ed. Cambridge: The University Press; 1995.

20. Liu Q, Leu MC. Fabrication of dental crowns by investment casting with rapid freeze prototyping generated ice patterns. In: Medical Device Materials: Proceeding of the Materials \&
Processes for Medical Devices Conference; 2003 Sep 8-11; Anaheim, CA, USA. p. 438-443. DOI: 10.1361/cp2003mpmd438.

21. ALJ - Associação Limeirense de Joias. Limeira - A Capital da Joia Folheada. Available from: <http://www.alj.org.br>. Access in: 02/09/2015.

22. Pantazopoulos G, Vazdirvanidis A. Characterization of the microstructural aspects of machinable $\alpha-\beta$ phase brass. Microscopy and Analysis. 2008;22:13-16.

23. Hsieh CC, Wang JS, Wu PTY, Wu W. Microstructural development of brass alloys with various $\mathrm{Bi}$ and $\mathrm{Pb}$ additions. Metals and Materials International. 2013;19(6):1173-1179.

24. Baker H, ed. ASM Metals Handbook, Alloy Phase Diagrams. Volume 3. Metals Park: ASM International; 1992.

25. heARTJOIA. Tutoriais e manuais de joalharia. Available from: $<$ http://www.heartjoia.com/4485-fundicao-cera-perdidamicrofundicao-ouro-prata $>$. Access in: 02/09/2015.

26. Wood MS, Hellawell A. Grain boundary precipitation in $\alpha \beta$ brass. Acta Metallurgica. 1961;9(5):428-433.

27. Simonen EP, Trivedi R. Edgewise growth of Widmanstätten alpha precipitates in brass. Acta Metallurgica. 1977;25(8):945950.

28. Korojy B, Fredriksson H. On solidification and shrinkage of brass alloys. International Journal of Cast Metals Research. 2009;22(1-4):183-186.

29. Boettinger WJ. The structure of directional solidified twophase Sn-Cd peritectic alloys. Metallurgical Transactions. 1974;5(9):2023-2031.

30. Zhou X, Hsu TY. Thermodynamics of the a and $\beta$ phases equilibria and ordering in $\mathrm{Cu}-\mathrm{Zn}$ system. Acta Metallurgica. 1989;37(11):3085-3090.

31. Miettinen J. Thermodynamic-kinetic model for the simulation of solidification in binary copper alloys and calculation of thermophysical properties. Computational Materials Science. 2006;36(4):367-380.

32. Scott DA. Metallography and microstructure of ancient and historic metals. $1^{\text {st }}$ ed. Los Angeles: The Getty Conservation Institute; 1991.

33. Konečá R, Fintová S. Copper and Copper Alloys: Casting, Classification and Characteristic Microstructures. In: Collini L, ed. Copper Alloys - Early Applications and Current Performance - Enhancing Processes. Rijeka: InTech; 2012. Available from: $<\mathrm{http}: / / \mathrm{www}$.intechopen.com/books/copperalloys-early-applications-and-current-performance-enhancingprocesses/copper-and-copper-alloys-casting-classification-andcharacteristics >. Access in: 11/04/2018.

34. Smallman RE, Ngan AHW. Physical Metallurgy and Advanced Materials. $7^{\text {th }}$ ed. Oxford: Butterworth-Heinemann; 2011.

35. Haque MM, Khan AA. Investigation on Structure and Properties of Brass Casting. Journal of Materials Science \& Technology. 2008;24(3):299-301.

36. Cooper Development Association. Free-Cutting Brass (UNS C36000) for Automatic Screw Machine Products; 2015. Available from: < http://www.copper.org/applications/rodbar/alloy360/ free_cutting.html $>$. Access in: 02/09/2015. 
37. Cooper Development Association. Properties of wrought and cast copper alloys; 2018. Available from: $<$ https://www. copper.org/resources/properties/db/basic-search.php $>$. Access in: $17 / 04 / 2018$.

38. Petch NJ. The cleavage strength of polycrystals. Journal of the Iron and Steel Institute. 1953;174:25-28.

39. Donelan P. Modelling microstructural and mechanical properties of ferritic ductile cast iron. Materials Science and Technology. 2000;16(3):261-269.

40. Ochoa F, Williams JJ, Chawla N. Effects of cooling rate on the microstructure and tensile behavior of a Sn-3.5wt.\%Ag solder. Journal of Electronic Materials. 2003;32(12):1414-1420.

41. Osório WR, Goulart PR, Garcia A, Santos GA, Moura Neto C. Effect of dendritic arm spacing on mechanical properties and corrosion resistance of $\mathrm{Al} 9 \mathrm{wt} \% \mathrm{Si}$ and $\mathrm{Zn} 27 \mathrm{wt} \% \mathrm{Al}$ alloys.
Metallurgical and Materials Transactions A. 2006;37(8):25252538.

42. Garcia LR, Osório WR, Garcia A. The effect of cooling rate on the dendritic spacing and morphology of Ag3Sn intermetallic particles of a SnAg solder alloy. Materials \& Design. 2011;32(5):3008-3012.

43. Osório WR, Peixoto LC, Garcia LR, Mangelinck-Noël N, Garcia A. Microstructure and mechanical properties of $\mathrm{Sn}-\mathrm{Bi}$, Sn-Ag and Sn-Zn lead-free solder alloys. Journal of Alloys and Compounds. 2013;572:97-106.

44. Satizabal LM, Costa D, Hainick GO, Moura DR, Bortolozo $\mathrm{AD}$, Osório WR. Microstructural and Hardness Evaluations of a Centrifuged $\mathrm{Sn}-22 \mathrm{~Pb}$ Casting Alloy Compared with a LeadFree SnAg Alloy. Metallurgical and Materials Transactions A. 2017;48(4):1880-1892. 